\title{
Determinants of utilisation of traditional birth attendant services by pregnant women in Ogbomoso, Nigeria
}

\author{
Awotunde O. T. ${ }^{1}$, Awotunde T. A. ${ }^{2}$, Fehintola F. O. ${ }^{3 *}$, Adesina S. A. ${ }^{1}$, Oladeji O. A. ${ }^{1}$, \\ Fehintola A. O. ${ }^{4}$, Ajala D. E. ${ }^{2}$
}

\begin{abstract}
${ }^{1}$ Department of Family Medicine, Bowen University Teaching Hospital, Ogbomosho, Oyo State. Nigeria
${ }^{2}$ School of Midwifery, Bowen University Teaching Hospital, Ogbomoso Oyo State, Nigeria

${ }^{3}$ Department of Community Medicine, Bowen university teaching Hospital, Ogbomoso Oyo State. Nigeria.

${ }^{4}$ Department of Obstetrics and Gynaecology, Bowen University Teaching Hospital, Ogbomoso, Oyo State, Nigeria
\end{abstract}

Received: 09 April 2017

Accepted: 02 May 2017

*Correspondence:
Dr. Fehintola A. O.,
E-mail: akintunds@yahoo.com

Copyright: (c) the author(s), publisher and licensee Medip Academy. This is an open-access article distributed under the terms of the Creative Commons Attribution Non-Commercial License, which permits unrestricted non-commercial use, distribution, and reproduction in any medium, provided the original work is properly cited.

\section{ABSTRACT}

Background: This study was designed to assess the determinants of utilization of Traditional Birth Attendants (TBAs) services by pregnant women in different communities in Ogbomoso, Nigeria.

Methods: This was a community- based cross-sectional study. Fisher's formula was used to calculate the sample size and a total of 270 eligible pregnant women were enrolled for the study using multistage sampling technique. Data was collected using pretested structured interviewer-administered questionnaire. Data analysis was done using SPSS version 20 and results were presented in frequencies and percentages.

Results: Factors found to have a significant influence on the utilization of TBA services in this study include: low educational status ( $p<0.001)$, lower socioeconomic status $(\mathrm{p}<0.001)$, and compassionate care given by the TBAs $(\mathrm{p}=0.004)$. Other factors include service proximity and lower cost of TBA services.

Conclusions: The impact of TBAs and their services cannot be overemphasized in the present state of maternal and child health in Nigeria. Lower educational status among others has been found to be a strong predictor of utilization of TBA services. There is, therefore, the need to improve the educational and socioeconomic status of women in order to allow them to access quality health care services that will safeguard their well-being. Inculcating compassionate care into orthodox healthcare delivery will go a long way to improve patronage and discourage TBA utilization.

Keywords: Determinants, Pregnant women, TBA utilization

\section{INTRODUCTION}

In the developing world, maternal and infant morbidity still remain a global concern, most especially in many Sub-Saharan African Countries. ${ }^{1,2}$ The estimate shows that there are more than 500 maternal mortalities out of every 100,000 live births in most African countries. ${ }^{3}$
It has been discovered that the increased maternal and infant mortality rate is blamed on many deliveries that took place at home with the help of untrained attendants. ${ }^{2-5}$ Deliveries conducted by TBAs have been shown to be associated with four times higher morbidity and mortality when compared with deliveries supervised by midwives and other health professionals. ${ }^{6}$ 
The practice of traditional birth attendant has caused a lot of havoc on the health of mother and child. Despite the introduction of modern health facilities, safe motherhood initiative program, free medical services etc., statistics showed that majority of children are born by TBAs both in rural and urban areas. The majority of deliveries are being carried out by TBAs which indicate that several deliveries still occur outside hospitals and health facilities. ${ }^{2,7,8}$

According to National Population Commission, one in every three births in Nigeria is attended by skilled personnel, thus confirming the fact that TBA utilization rate in Nigeria is still very high. ${ }^{9,10}$

Studies conducted in some African countries have shown that most pregnant women still prefer TBAs services to orthodox services due to several reasons. Some of these include economic and pragmatic reasons, unaffordable fees aggravated by the low economic status of the community members, and embarrassment by health care providers. Other reasons found were the trust and tradition that the TBAs exhibit. Some of the respondents claimed that TBAs shared the same culture with them and that they were long-serving members of the community. Furthermore, difficult access to health personnel and social distance between the community and village midwife were among the issues raised. ${ }^{11}$

Considering the foregoing, it is imperative to study the determinants of utilization of TBA services by pregnant women in Ogbomoso, Nigeria. This will go a long way to influence policy making on maternal and child health in Nigeria.

\section{METHODS}

It was a community-based cross-sectional study carried out between January and May 2016 in Ogbomoso South and Ogbomoso North Local government areas in Oyo State, Nigeria. The two Local Government Areas (LGA) within Ogbomoso Township (Ogbomoso North and South) are semi-urban. These two LGAs have an estimated population of 300,000 according to 2006 census (Federal Republic of Nigeria, Official Gazette, 2009). ${ }^{12}$

About 100 TBAs were registered in the Primary Health Care Units of both North and South LGAs in Ogbomoso. Pregnant women attending these TBAs were recruited for the study. Non-consenting pregnant women attending these TBAs were excluded from the study. Eligible respondents were selected using multi-stage sampling procedure.

The minimum sample size was determined by using the Fishers formula. ${ }^{13}$ Using a prevalence rate i.e. the proportion of pregnant women utilizing TBAs services in Ogbomoso. (Not known presently, therefore $50 \%$ is chosen, extrapolated from National Demographic Health
Survey, 2008 the sample size needed to achieve a precision of $5 \%$ at $95 \%$ confident interval was obtained from equation $\mathrm{N}=\mathrm{Z}^{2} \mathrm{P}(1-\mathrm{P}) / \mathrm{d}^{2}$ where $\mathrm{d}=0.05, \mathrm{Z}=1.96$ and $\mathrm{P}=0.5 .^{9}$ The calculated sample size was 246 . To allow for non-respondents and those who will be excluded due to breach in the study protocol, a total of 270 subjects were enrolled for the study.

Data was collected using a pre-tested semi-structured interviewer-administered questionnaire which was administered by trained research assistants

\section{Statistical analysis}

Each questionnaire was given a unique code and entered into SPSS version 20. Frequencies of variables were used to check for missed values and outliers. Univariate analysis was carried out to determine the frequency distribution of the age groups, marital status, the level of education, occupation, religion and ethnicity of respondents. Bivariate analysis using Chi-square test was carried out to determine factors influencing utilization of TBAs services. For all statistical analysis, a P-value less than 0.05 was considered significant.

For ease of analysis, utilization of TBAs services was categorized into full and partial. Clients who utilized TBA services and also booked for antenatal care in other hospitals were regarded as partial utilizers while those who used only TBA services as full utilizers.

\section{RESULTS}

From the Table 1, the mean age of the respondents is $27.9 \pm 5.4$ years with the majority of the respondents $(55.2 \%)$ within the age group 20-29years. The majority of the respondents have a secondary education $(67.8 \%)$. About $70.4 \%$ of the respondents belong to the low social classes shown in Table 1.

The majority of the respondents, $63.7 \%$ lived within a distance of less than $1 \mathrm{~km}$ to the nearest health facility while only $44.8 \%$ lived within less than a kilometer from the nearest TBA center.

From the Table 2 above, the majority of the respondents $(80.7 \%)$ mentioned compassionate care by the TBAs as a reason why they utilize TBAs services instead of orthodox services. But about $30 \%$ of the respondents claimed that they are not aware of another maternity centers other than TBAs.

Some other respondents mentioned cultural acceptability $(67.4 \%)$, the proximity of TBAs to their dwelling place $(47 \%)$ and cheaper service $(65.2 \%)$ as shown in the table.

Amongst other reasons for utilizing TBA services, prayer was mentioned by $(74.8 \%)$ of the respondents. However, a few stated prompt services (7.0\%), clinic schedule 
(3.3\%), family support $(2.6 \%)$ and spiritual counseling $(1.5 \%)$ as reasons for utilizing the TBA services.

Table 1: Socio-demographic characteristics of the respondents.

\begin{tabular}{|c|c|c|}
\hline Variables & \multicolumn{2}{|c|}{ Value $(n=270)$} \\
\hline Mean Age & \multicolumn{2}{|c|}{27.9} \\
\hline SD & \multicolumn{2}{|l|}{5.4} \\
\hline Age Group (Yrs) & Frequency & $\%$ \\
\hline$<20$ & 12 & 4.4 \\
\hline $20-29$ & 149 & 55.2 \\
\hline $30-39$ & 101 & 37.4 \\
\hline $40-49$ & 8 & 3 \\
\hline \multicolumn{3}{|l|}{ Religion } \\
\hline Christianity & 229 & 84.8 \\
\hline Islam & 41 & 15.2 \\
\hline \multicolumn{3}{|l|}{ Marital status } \\
\hline Never married & 14 & 5.2 \\
\hline Married & 256 & 94.8 \\
\hline \multicolumn{3}{|l|}{ Occupation } \\
\hline Civil servant & 29 & 10.7 \\
\hline Unemployed & 20 & 7.4 \\
\hline Artisan & 95 & 35.2 \\
\hline Private employee & 126 & 46.7 \\
\hline \multicolumn{3}{|l|}{ Parity } \\
\hline None & 73 & 27 \\
\hline one child & 74 & 27.4 \\
\hline 2-5 children & 122 & 45.2 \\
\hline Over 5 children & 1 & 0.4 \\
\hline \multicolumn{3}{|l|}{ Level of Education } \\
\hline Primary & 21 & 7.8 \\
\hline Secondary & 183 & 67.8 \\
\hline Post-secondary & 66 & 24.4 \\
\hline \multicolumn{3}{|l|}{ Ethnic Group } \\
\hline Yoruba & 266 & 98.5 \\
\hline Igbo & 1 & 0.4 \\
\hline Others & 3 & 1.1 \\
\hline \multicolumn{3}{|l|}{ Social class } \\
\hline Lower Class & 190 & 70.4 \\
\hline Middle Class & 35 & 13.0 \\
\hline Upper Class & 45 & 16.7 \\
\hline \multicolumn{3}{|c|}{ Distance from TBA center from home } \\
\hline$<1 \mathrm{~km}$ & 121 & 44.8 \\
\hline $1-2 \mathrm{~km}$ & 53 & 19.6 \\
\hline $3-4 \mathrm{~km}$ & 50 & 18.5 \\
\hline$\geq 5 \mathrm{~km}$ & 46 & 17.0 \\
\hline \multicolumn{3}{|c|}{ Distance of nearest health facility } \\
\hline$<1 \mathrm{~km}$ & 172 & 63.7 \\
\hline $1-2 \mathrm{~km}$ & 54 & 20.0 \\
\hline $3-4 \mathrm{~km}$ & 21 & 7.8 \\
\hline$\geq 5 \mathrm{~km}$ & 23 & 8.5 \\
\hline
\end{tabular}

Table 3 showed that respondents with lower educational level are more likely to utilize TBA services only compared to their more educated counterparts who tend to seek antenatal care from orthodox centers in addition to TBA services.
It also revealed a significant relationship between the social class of the respondents, $(\mathrm{p}<0.001)$ and compassionate care by the TBAs $(p=0.004)$ as other factors influencing utilization of TBA services.

Table 2: Reasons for utilizing TBAs services.

\begin{tabular}{|llll|}
\hline \multicolumn{1}{|l}{ Variable } & Response & Frequency & $\%$ \\
\hline $\begin{array}{l}\text { TBA services } \\
\text { cheaper }\end{array}$ & Yes & $176^{*}$ & 65.2 \\
\hline $\begin{array}{l}\text { TBA services } \\
\text { cultural acceptable }\end{array}$ & Yes & $182^{*}$ & 67.4 \\
\hline $\begin{array}{l}\text { TBA services } \\
\text { proximity }\end{array}$ & Yes & $127^{*}$ & 47 \\
$\begin{array}{l}\text { TBA- } \\
\text { compassionate } \\
\text { care }\end{array}$ & Yes & $218^{*}$ & 80.7 \\
\hline $\begin{array}{l}\text { TBA-only } \\
\text { maternity } \\
\text { that I know }\end{array}$ & Yes & $81^{*}$ & 30 \\
\hline $\begin{array}{l}\text { Prayer } \\
\text { Convenient clinic } \\
\text { schedule }\end{array}$ & $202^{*}$ & 74.8 \\
\hline $\begin{array}{l}\text { Credit facility } \\
\text { Prompt service }\end{array}$ & $9 *$ & 3.3 \\
\hline Family support & & $9^{*}$ & 0.7 \\
\hline $\begin{array}{l}\text { Spiritual } \\
\text { counselling }\end{array}$ & $7^{*}$ & 7.0 \\
\hline No response & $41^{*}$ & 2.6 \\
\hline Multiple responses noted & & 1.5 \\
\hline
\end{tabular}

Table 4 showed the logistic regression of the determinants of utilization of TBA services among the respondents. Compared to respondents with secondary education or lower, those with post-secondary school education were $50 \%$ less likely to utilize TBA services only $(\mathrm{OR} 0.5, \mathrm{CI}=0.42-0.94, \mathrm{P}=0.02)$.

Respondents who were of higher socioeconomic status were $90 \%$ less likely to utilize TBA services only compared to their counterparts with lower socioeconomic status (OR 0.1, $\mathrm{CI}=0.1-0.45, \mathrm{P}=0.008$ ). Respondents who believed that TBAs offer more compassionate care than orthodox healthcare providers were twice more likely to utilize TBA services only compared to those who believed otherwise (OR 2.12, $\mathrm{CI}=$ 1.39-5.87, $\mathrm{P}=0.003)$.

\section{DISCUSSION}

In Nigeria, just like most developing countries a number of pregnant women still prefer to utilize TBA services than seek health care from health facilities.

Studies have shown adverse effects of their practices on both mother and child leading to high maternal and infant mortality ratio. ${ }^{2-6}$ 
Table 3: Relationship between selected variables and utilization status of TBA services.

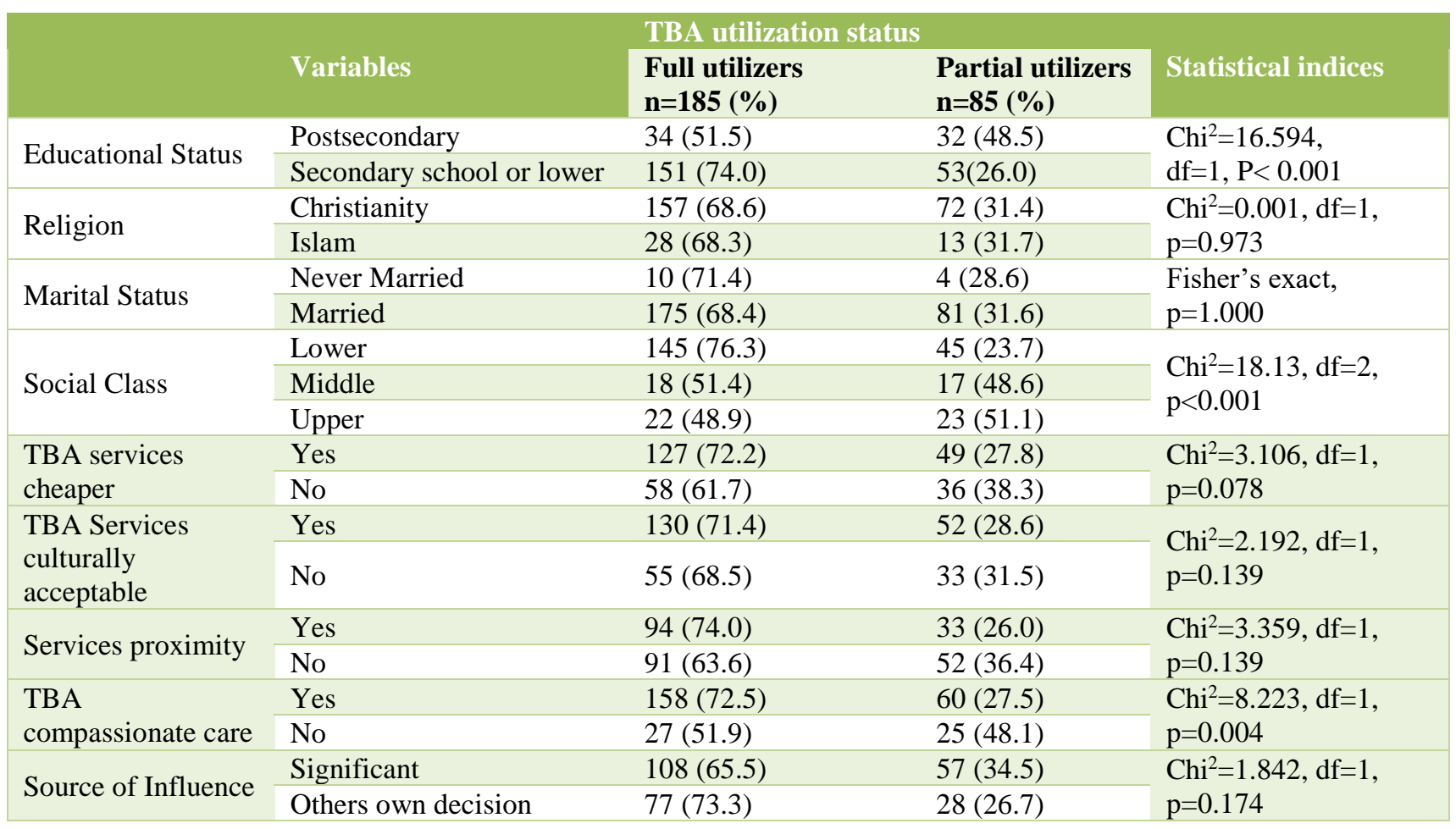

Table 4: Logistic regression showing determinants of utilization TBA services among respondents.

\begin{tabular}{|llll|}
\hline Variables & \multicolumn{3}{c}{ TBA full utilisation } \\
\hline & OR $185(\%)$ & $95 \%$ CI & P \\
\hline $\begin{array}{l}\text { Educational status } \\
\text { (Ref=sec. School and } \\
\text { below Postsecondary }\end{array}$ & 0.5 & $0.42-0.94$ & 0.02 \\
\hline $\begin{array}{l}\text { Religion (Ref=Xtianity) } \\
\text { Islam }\end{array}$ & 0.25 & $0.22-1.82$ & 0.324 \\
\hline $\begin{array}{l}\text { Social Class (Ref=lower) } \\
\text { higher }\end{array}$ & 0.1 & $0.1-0.45$ & 0.008 \\
\hline $\begin{array}{l}\text { TBA services cheaper } \\
\text { (Ref=No) Yes }\end{array}$ & 2 & $0.52-2.35$ & 0.542 \\
\hline $\begin{array}{l}\text { TBA Services culturally } \\
\text { acceptable (Ref=No) Yes }\end{array}$ & 0.5 & $0.40-2.82$ & 0.123 \\
\hline $\begin{array}{l}\text { Services proximity } \\
\text { (Ref=No) Yes }\end{array}$ & 2.5 & $0.48-3.99$ & 0.54 \\
\hline $\begin{array}{l}\text { TBA compassionate care } \\
\text { (Ref=No) Yes }\end{array}$ & 2.12 & $1.39-5.87$ & 0.003 \\
\hline
\end{tabular}

A total of 270 pregnant women within the reproductive age group 15-49 years were included. The mean age of the respondents was $27.9 \pm 5.4$ years. Most of the women fell within the age range of 20-29 years $(55.2 \%)$. The low proportion of women in both extremes of reproductive life observed in this study is noteworthy because of the high-risk features associated with these age groups $(\leq 20$ and 40-49 years respectively). Previous studies observed similar findings. ${ }^{2,14}$ However, in a study done by
Akenzua et al reported by Salako, TBAs were found to be managing pregnancies of high risk in adolescents and elderly primigravida. ${ }^{15-17}$ Involvement of TBAs in managing pregnancies at the extremes of reproductive life which are beyond their scope indicates a lack of risk assessment and can result in high maternal and perinatal mortality and morbidity.

It was noted in this study that majority of respondents were of lower socioeconomic status and lower level of education (70.4\% and $75.6 \%$ respectively). This finding was similar to that of the study done in the northern part of Nigeria where the majority of the pregnant women utilizing TBA services were of a lower socio-economic class and lower educational level. ${ }^{18}$ Also, the majority of the respondents lived within a distance of less than $1 \mathrm{~km}$ from a health care facility. This was in contrast to previous studies where the long distance between patient's home and health care facility was a reason for utilizing TBA services. ${ }^{6,11,19}$

The determinants of utilization of TBA services found in this study were: lower educational status, lower socioeconomic status and more compassionate care by the TBAs. It was noted that respondents with secondary school education or lower were $50 \%$ more likely to utilize TBA services only compared to those with higher education. Similar findings were reported in Malawi, Zambia, and Nigeria as well. ${ }^{2,20,21}$ Also, a similar study conducted in Sierra Leone agreed with this finding as it revealed that there is a positive association between low 
literacy and utilization of TBA services. ${ }^{22}$ Contrary to this, however, a study done in Southwest Nigeria revealed that most mothers irrespective of their level of education still utilize traditional homes which to some are safer and have less complication. ${ }^{23}$

In the same vein, the social class of the respondents was significantly related to the TBA utilization status. It was revealed that majority of the respondents $(70.4 \%)$ belong to the lower socio-economic level. Doctor and Dahiru reported similar findings. ${ }^{18}$ The lower the socioeconomic level the more likely a woman is to opt for TBA services which she may think is cheaper than hospital services. With an increasing cost of health care and rate of unemployment, the future looks bleak for the low social class individuals. This finding is corroborated by a study that reported that women of higher socioeconomic status are able to make wiser decisions concerning their health than their counterparts in the lower social class. ${ }^{24}$

The TBAs received a remarkable level of patronage from pregnant women by the majority of respondents, due to the fact that they provide compassionate care more than the orthodox health workers. This finding is not different from that of other studies where similar results were reported. In comparison, a study done in Ogun State South West Nigeria, about $(43.5 \%)$ of the respondents claimed that TBA provides more compassionate care. These finding compared well with those of West Java province in Indonesia and studies conducted in several parts of Nigeria. ${ }^{11}$ Other factors like service proximity, cultural acceptability and low cost of TBA services did not significantly influence utilization of TBA services. This was in contrast to findings of other previous studies where TBA services were considered culturally more acceptable, cheaper and were easily accessible (Mboye, Opiah, and Dorwie).

This present study should be interpreted in the light of some limitations. Being a cross-sectional study, causality may be difficult to ascertained. Also, Paucity of local data on utilization of TBAs services by pregnant women possibly as a result of difficulty in penetrating the TBAs circle could be a limiting factor.

\section{CONCLUSION}

The TBAs play central roles in the present state of maternal and child health in Nigeria. Lower educational and socio-economic status among others has been found to strongly influence utilisation of TBA services in this study. There is, therefore, the need to improve the educational and socioeconomic status of women in order to allow them to access quality health care services that will safeguard their well-being. Inculcating compassionate care into orthodox healthcare delivery will go a long way to improving uptake of orthodox health care delivery.

\section{ACKNOWLEDGMENTS}

Authors would like to thank Mrs. Priscilla Adumoah Attafuah of the Nursing Department, of Valley View University, Accra, Ghana, and Mr. Sunday Oladunjoye of Bowen University Teaching Hospital, Ogbomoso, Oyo State, Nigeria for their inputs in writing of this article.

Funding: No funding sources

Conflict of interest: None declared

Ethical approval: The study was approved by the Institutional Ethics Committee

\section{REFERENCES}

1. Bryce J, Daelmans B, Dwivedi A, Fauveau V, Lawn J, Mason E, et al. Countdown Coverage Writing Group; Countdown to 2015 Core Group. Countdown to 2015 for maternal, newborn, and child survival: the 2008 report on tracking coverage of interventions. Lancet. 2008;371(9620):1247-58.

2. Ebuehi OM, Akintujoye I. Perception, and utilization of traditional birth attendants by pregnant women attending primary health care clinics in a rural Local Government Area in Ogun State, Nigeria. Int $\mathbf{J}$ Womens Health. 2012;4:25-34.

3. Chou D, Inoue M, Mathers C, Moller A, Oestergaard M, Say L, et al. Trends in maternal mortality: 1990 to 2010. WHO-UNICEF UNFPA and the World Bank estimates. 2012.

4. Lawn JE, Lee AC, Kinney M, Sibley L, Carlo WA, Paul VK et al. Two million intrapartum-related stillbirths and neonatal deaths: where, why, and what can be done? Int J Gynecol Obstet. 2009;107:S5S19.

5. Monjok E, Essien E, Smesny A, Okpokam S. A training need for rural primary care in Nigeria. $\mathrm{J}$ Obstet Gynaecol. 2010;30(8):833-5.

6. Opiah M, Osayi T, Afolayan J, AdeyanjuAB UA. Factors influencing patronage of traditional birth attendants for delivery and newborn care in amassoma community, Southern IJAW local government area, Bayelsa State. Bull Sci Assoc Nigeria. 2010;29:27-32.

7. Ofili A, Okojie O. Assessment of the role of traditional birth attendants in maternal health care in Oredo Local Government Area, Edo State, Nigeria. J Comm Medicine Prim Health Care. 2005;17(1):5560.

8. M'Cormack-Hale FA, Beoku-Betts J. General Introduction. Afr Asian Studies. 2015;14(1-2):8-17.

9. Abuja N. National Population Commission and ICF Macro; 2009. National Population Commission (NPC)[Nigeria] and ICF Macro Nigeria Demographic Health Survey. 2008.

10. Abimbola S, Okoli U, Olubajo O, Abdullahi MJ, Pate MA. The midwives service scheme in Nigeria. PLoS Med. 2012;9(5):e1001211.

11. Titaley CR, Hunter CL, Dibley MJ, Heywood P. Why do some women still prefer traditional birth 
attendants and home delivery?: a qualitative study on delivery care services in West Java Province, Indonesia. BMC Pregnancy Childbirth. 2010;10(1):1.

12. Commission NNP. Legal notice on the publication of 2006 Census final results In: Federal Republic of Nigeria official Gazette No 2. Abuja; 2009.

13. Araoye MO. Research methodology with statistics for health and social sciences. Ilorin, Nigeria: Nathadex Publishers; 2004.

14. Kirchengast S, Hartmann B. Advanced maternal age is not only associated with newborn somatometric but also with the mode of delivery. Annals Human Biol. 2003;30(1):1-12.

15. Okafor CB. Availability and use of services for maternal and child health care in rural Nigeria. Int $\mathrm{J}$ Gynecol Obstet. 1991;34(4):331-46.

16. Akenzua GI, Akpovi SU, Ogbeide O. Maternal and child care in rural areas: the role of traditional birth attendants in the Bendel State of Nigeria. J Trop Pediatr. 1981;27(4):210-4.

17. Salako AA. Letter to the Editor: The traditional birth attendant and the high Nigerial's maternal mortality. Nigerian J Clini Prac. 2002;5(1):69-70.

18. Doctor HV, Dahiru T. Utilization of non-skilled birth attendants in Northern Nigeria: a rough terrain to the health-related MDGs. Afr J Reprod Health. 2010;14(2):37-45.

19. Onah HE, Ikeako LC, Iloabachie GC. Factors associated with the use of maternity services in Enugu, southeastern Nigeria. Social Sci Medicine. 2006;63(7):1870-8

20. Oshonwoh E, Nwakwuo G, Ekiyor C. Traditional birth attendants and women's health practices: A case study of Patani in Southern Nigeria. J Community Health. 2014;38(2):349-56.

21. Mpembeni RN, Killewo JZ, Leshabari MT, Massawe SN, Jahn A, Mushi D et al. Use pattern of maternal health services and determinants of skilled care during delivery in Southern Tanzania: implications for achievement of MDG-5 targets. BMC pregnancy Childbirth. 2007;7(1):1.

22. Dorwie FM, Pacquiao DF. Practices of traditional birth attendants in Sierra Leone and perceptions by mothers and health professionals familiar with their care. J Transcultural Nursing. 2013:1043659613503874.

23. Ewa E, Lasisi C, Maduka S, Ita A, Ibor U, Anjorin O. Perceived factors influencing the choice of antenatal care and delivery centres among childbearing women in Ibadan North South-Western, Nigeria. Ethiopian J Environ Studies Managem. 2012;5(4):373-83.

24. Mbonye AK, Neema S, Magnussen P. Preventing malaria in pregnancy: a study of perceptions and policy implications in Mukono district, Uganda. Health Policy Planning. 2006;21(1):17-26.

Cite this article as: Awotunde OT, Awotunde TA, Fehintola FO, Adesina SA, Oladeji OA, Fehintola AO, et al. Determinants of utilisation of traditional birth attendant services by pregnant women in Ogbomoso, Nigeria. Int J Reprod Contracept Obstet Gynecol 2017;6:2684-9. 